\title{
Enzyme inactivation related to a hyperoxidant state during conidiation of Neurospora crassa
}

\author{
Ivonne Toledo, ${ }^{1}$ Jesús Aguirre ${ }^{2}$ and Wilhelm Hansberg ${ }^{2}$ \\ Author for correspondence: Wilhelm Hansberg. Tel: +525 6225627. Fax: +5256225630.
e-mail: whansber@ifcsun1.ifisiol.unam.mx
}

1 Centro de Investigación
sobre Fijación de
Nitrógeno, Universidad
Nacional Autónoma de
México, Ap. Postal 565-A,
Cuernavaca 62280, Mor.
Mexico
2 Instituto de Fisiología
Celular, Universidad
Nacional Autónoma de
México, Ap. Postal 70-242,
04510 Mexico DF

\begin{abstract}
The conidiation process of Neurospora crassa is characterized by three morphogenetic steps: hyphal adhesion, aerial hyphal formation, and production of conidia. Previous data indicated the occurrence of a hyperoxidant state at the onset of all three morphogenetic steps. Because glutamine synthetase (GS) and the biosynthetic glutamate dehydrogenase [GDH(NADP)] enzymes are susceptible to inactivation by reactive oxygen species, we followed these enzyme activities during conidiation and under different physiological conditions and related them to the hyperoxidant states and morphogenesis. Loss of GS activity occurred prior to all three morphogenetic steps, coinciding with an increase in total protein oxidation. Oxidized GS polypeptides were detected during hyphal adhesion. Loss of GDH(NADP) activity also occurred during hyphal adhesion and before aerial hyphal formation; the enzyme polypeptide and activity decreased in the adhered hyphae to low values and no GDH(NADP) was detected in aerial hyphae. The catabolic GDH [GDH(NAD)] behaved in an opposite manner, increasing its activity during hyphal adhesion and aerial hyphae development. These results are discussed with regard to cell differentiation and the conidiation process in $\boldsymbol{N}$. crassa.
\end{abstract}

Keywords: oxygen radicals, sporulation, protein oxidation, glutamine synthetase, glutamate dehydrogenase

\section{INTRODUCTION}

Micro-organisms adapt to grow under different environmental conditions, even to relatively extreme ones. Most micro-organisms differentiate, for example by sporulation, when continuation of growth is impaired. Both the growth state and the differentiated state are stable states. Thus a differentiation process can be considered as a transition between stable states via an unstable state (Hansberg \& Aguirre, 1990).

A synchronous process of conidiation is started when an aerated liquid culture of Neurospora crassa is filtered and the resulting mycelial mat is exposed to air (Toledo et al., 1986; Springer \& Yanofsky, 1989). Hyphae in direct contact with air adhere to each other within $40 \mathrm{~min}$ and the adhered hyphae start growing aerial hyphae after $2.5 \mathrm{~h}$ exposure to air. Unadhered hyphae covered by adhered

Abbreviations: GS, glutamine synthetase [L-glutamate:ammonia ligase] (EC 6.3.1.2); GDH(NADP), biosynthetic glutamate dehydrogenase [Lglutamate: NADP oxidoreductase (deaminating)] (EC 1.4.1.4); GDH(NAD), [L-glutamate: NAD oxidoreductase (deaminating)] (EC 1.4.1.2). hyphae do not differentiate. Conidia are formed at the tips of the branched aerial hyphae after $9 \cdot 5 \mathrm{~h}$ (Toledo et al., 1986). Thus in the conidiation process of $N$. crassa there are three transitions between stable states: the first one, from the loose hyphae to the adhered hyphae, takes about $30 \mathrm{~min}$; the second one, from the adhered hyphae to the aerial hyphae takes around $10 \mathrm{~h}(2 \cdot 5-12.5 \mathrm{~h})$; and the third one, from the aerial hyphae to the conidia, takes about $5 \mathrm{~h}$ $(9 \cdot 5-14 \cdot 5 \mathrm{~h})$.

Using this conidiation system, it was shown that glutamine synthetase (GS) and the biosynthetic glutamate dehydrogenase [GDH(NADP)] were lost in the adhered hyphae but preserved in the unadhered hyphae. A marked increase in proteolysis was also limited to the adhering hyphae (Cárdenas \& Hansberg, 1984). This increased protein catabolism was preceded by a peak of protein oxidation (Toledo \& Hansberg, 1990). GS and GDH(NADP) were susceptible to oxidation in vitro by reactive oxygen species, giving rise to polypeptides with similar molecular masses but different isoelectric points. The oxidized GS was also shown to be more susceptible to attack by endogenous proteases. Oxidized polypeptides 
were detected in vivo under conditions in which these enzymes are degraded, and degradation of both was dependent on the presence of air (Aguirre \& Hansberg, 1986; Aguirre et al., 1989). It was hypothesized that, in hyphae exposed directly to air, a hyperoxidant state developed, characterized by increased generation of reactive oxygen species in amounts surpassing the cellular competence to neutralize them. Reactive oxygen species in the adhering hyphae would oxidize GS, GDH(NADP) and many other proteins; a massive proteolysis would be a consequence of protein oxidation (Hansberg \& Aguirre, 1990).

A redox imbalance, determined by a transient oxidation of $\mathrm{NAD}(\mathrm{P}) \mathrm{H}$ and glutathione was detected during hyphal adhesion. Glutathione disulphide excretion was observed (Toledo et al., 1991), which indicates oxidative stress (Sies \& Akerboom, 1984). Oxidation of $\mathrm{NAD}(\mathrm{P}) \mathrm{H}$ and glutathione was also detected at the start of aerial hyphal growth and formation of conidia (I. Toledo, P. Rangel \& W. Hansberg, unpublished observation). Recently, we observed increased chemiluminescence related to reactive oxygen species in association with hyphal adhesion, the start of aerial growth and conidia formation (Hansberg et al., 1993). It was concluded that a hyperoxidant state occurred at the start of all three morphogenetic steps during conidiation. We have proposed that cell differentiation arises when cells invoke mechanisms that tend to avoid dioxygen to compensate a hyperoxidant state (Hansberg \& Aguirre, 1990).

In this paper we provide support to our proposition by showing that the loss of GS and GDH(NADP) enzyme activities correlates with a hyperoxidant state that precedes appearance of the differentiated cellular structures.

\section{METHODS}

Strains and cultures. Wild-type $N$. crassa strain $74 \mathrm{~A}$ and $a m$ 132, which is a GDH(NADP) deletion mutant strain (Kinsey \& Hung, 1981), were obtained from the Fungal Genetics Stock Center, University of Kansas Medical Center. Conidia were obtained from slant cultures in minimal medium (Vogel, 1964), supplemented with $1.5 \%(\mathrm{w} / \mathrm{v})$ sucrose, grown for $3 \mathrm{~d}$ in the dark at $29^{\circ} \mathrm{C}$ followed by $2 \mathrm{~d}$ in the light at $25^{\circ} \mathrm{C}$. Stocks of conidia in distilled water were kept at $-70^{\circ} \mathrm{C}$. Liquid cultures (in Erlenmeyer flasks with an air to liquid ratio of 3 ) were grow'n for $12 \mathrm{~h}$ at $30^{\circ} \mathrm{C}$ from a conidial inoculum of $10^{6} \mathrm{cells} \mathrm{m}^{-1}$ Vogel minimal medium supplemented with $1.5 \%$ sucrose. Aeration was provided by a gyratory shaker at 240 r.p.m. Cultures of the am-132 strain were supplemented with $5 \mathrm{mM}$ glutamate. In one experiment a $200 \mathrm{ml}$ liquid culture, after $12 \mathrm{~h}$ growth, was diluted with $710 \mathrm{ml}$ fresh medium, fractionated in amounts of $3,4,5$ and $6.3 \mathrm{ml}$ in $22 \mathrm{ml}$ vials, and incubated for $3 \mathrm{~h}$ more under the same conditions. A similar culture was diluted with $30 \mathrm{mM}$ phosphate buffer ( $\mathrm{pH} \mathrm{6.1)}$ instead of medium and incubated for another $3 \mathrm{~h}$ in closed $60 \mathrm{ml}$ Falcon tubes, filled to the top to eliminate air. The culture then fractionated in amounts of 3,4 and $5 \mathrm{ml}$ and incubated for another $3 \mathrm{~h}$. Another set of vials with different volumes were filtered through cheesecloth to separate the adhered from the unadhered mycelium and the amount of protein was determined in both. Incubation of mycelial mats and separation of adhered, unadhered, and aerial hyphae was done as described by Toledo et al. (1986). Mycelia were harvested by filtration, dehydrated with an excess of acetone and stored at $-20^{\circ} \mathrm{C}$ until used.

Enzyme determinations. Cell extracts for enzyme determination were prepared as described before (Aguirre \& Hansberg, 1986; Aguirre et al., 1989); GS activity was determined by the method of Ferguson \& Sims (1971). Transferase activity is expressed as $\mu \mathrm{mol} \gamma$-glutamyl hydroxamate produced at $30^{\circ} \mathrm{C}$ (mg protein) ${ }^{-1} \mathrm{~min}^{-1}$. GDH activities were measured following the oxidation of either NADPH for the biosynthetic enzyme or $\mathrm{NADH}$ for the catabolic one following the method of Fincham (1957). Specific activities are expressed as mol oxidized NADPH or $\mathrm{NADH} \mathrm{min} \mathrm{m}^{-1}(\mathrm{mg} \text { protein })^{-1}$ at $30^{\circ} \mathrm{C}$. Protein was determined by the Lowry method.

Protein degradation and carbonyl content. [U- $\left.{ }^{14} \mathrm{C}\right]$ Leucine $\left[0.2 \mathrm{ml}\right.$ of $\left.328 \mathrm{mCi} \mathrm{mol}^{-1}\left(12 \cdot 1 \mathrm{GBq} \mathrm{mol}^{-1}\right)\right]$ was added to a $170 \mathrm{ml}$ liquid culture grown for $9 \mathrm{~h}$. After $2.5 \mathrm{~h}$ incubation, unlabelled leucine powder was added to attain $10 \mathrm{mM}$ concentration and incubated for another $1 \mathrm{~h}$. Then mycelial mats were made by filtering $25 \mathrm{ml}$ culture and exposed to air. At different times a mycelial mat was homogenized and samples were taken for protein and radioactivity determination. Total protein was extracted by the method described by Toledo \& Hansberg (1990), which is designed to eliminate all lipids, since these interfere with carbonyl content determination. Total protein samples of $20 \mu \mathrm{l}$ were precipitated with TCA, filtered, dried and radioactivity determined in a scintillation counter. Samples of $100 \mu \mathrm{l}$ were used for carbonyl content determination according to Ahn et al. (1987), with minor modifications as described by Toledo \& Hansberg (1990).

Immunoprecipitation. Immunization, antibody extraction and immunoprecipitation of GS and GDH(NADP) were done as described by Aguirre \& Hansberg (1986), and Aguirre et al. (1989). Briefly, samples of cell extracts $(0.4$ and $0.6 \mathrm{mg}$ protein) were immunoprecipitated for $12 \mathrm{~h}$ at $4{ }^{\circ} \mathrm{C}$ with a rabbit polyclonal antibody against purified GS (Sánchez et al., 1978), for $4 \mathrm{~h}$ at $4{ }^{\circ} \mathrm{C}$ with a rabbit polyclonal antibody against purified GDH(NADP). The GS and GDH(NADP) immunoprecipitates were centrifuged through discontinuous sucrose gradients $(1 \mathrm{M}$ and $0.5 \mathrm{M}$ sucrose), the pellets were suspended and analysed by electrophoresis.

Electrophoresis. The GS immunoprecipitates were analysed by two-dimensional PAGE following the method of O'Farrell (1975). The final voltage pulse in the first dimension was omitted and the second dimension was run with urea. The GDH(NADP) immunoprecipitates were analysed by SDSPAGE following the method of Laemmli. The gels were stained with Coomassie R-250.

\section{RESULTS AND DISCUSSION}

\section{GS oxidation during conidiation}

We have explained the loss of GS activity detected in the adhered hyphae as a result of an enzyme oxidative inactivation during air exposure of hyphae (Hansberg \& Aguirre, 1990). However, loss of activity could also be due to nutrient deprivation of the mycelial mat. To show that GS activity loss is related to air exposure and not to starvation, the following experiment was done. A liquid culture in growing medium was divided into five parts; four of them were aerated at different air-to-liquid ratios and the fifth was transferred to a phosphate buffer and was incubated without aeration. GS activity was measured after $3 \mathrm{~h}$ incubation. The higher the air to liquid ratio of the culture, the lower the GS activity detected (Fig. 1). In 


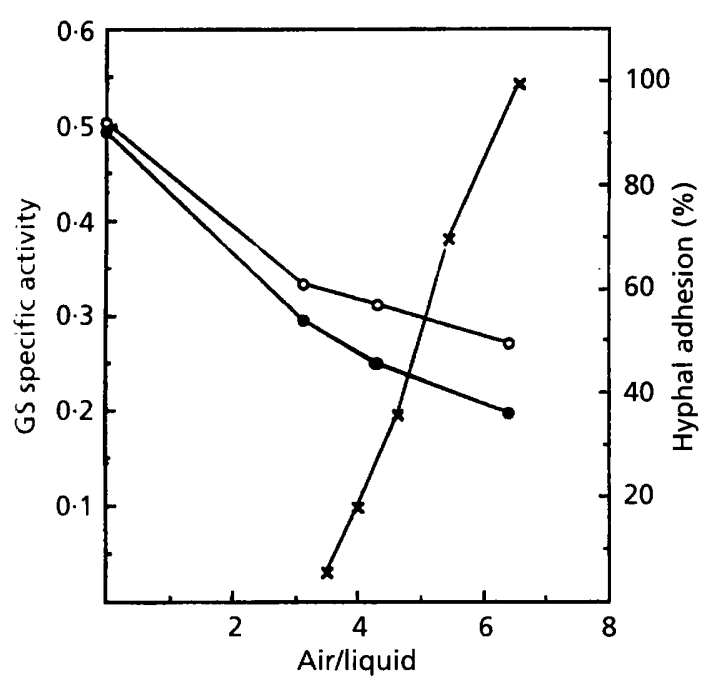

Fig. 1. GS activity and hyphal adhesion at different air-to-liquid ratios. A liquid culture was divided and aerated at different airto-liquid ratios, 0 , GS specific activity after $3 \mathrm{~h}$ incubation; $O$, GS specific activity after $3 \mathrm{~h}$ preincubation in phosphate buffer without aeration followed by transfer to fresh growth medium and incubation at different air-to-liquid ratios for another $3 \mathrm{~h}$; $x$, hyphal adhesion. Mean values of two experiments.

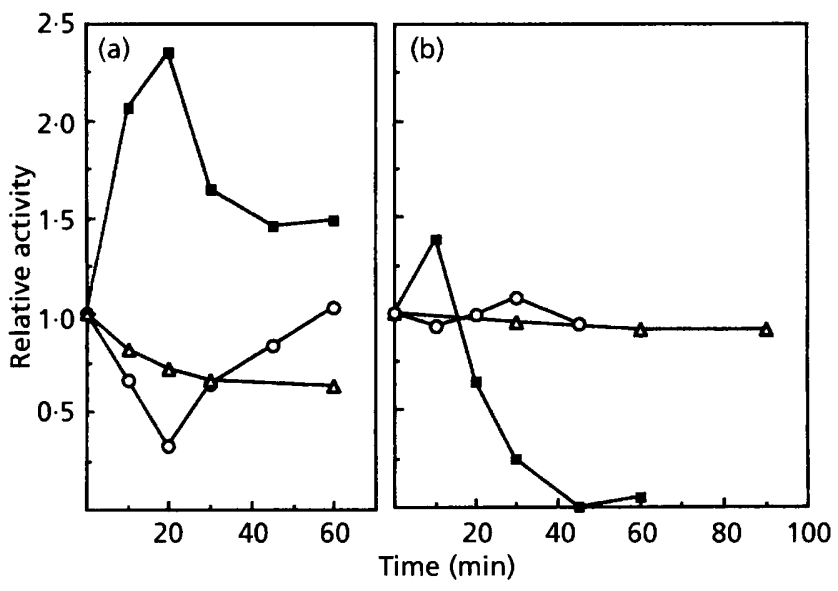

Fig. 2. GS activity and protein degradation in relation to total protein oxidation during hyphal adhesion. (a) $O$, Relative GS activity. Initial specific activity $\left[1.87 \mathrm{U}\left(\mathrm{mg}^{2} \text { protein }\right)^{-1}\right]$ was taken as 1 ; mean value of four experiments, mean standard deviation $16.6 \pm 2.5 \%$. $\triangle$, Relative specific radioactivity in total protein; initial specific radioactivity [251.6 c.p.m. ( $\mu$ g protein) ${ }^{-1}$ ] was taken as 1. Q Relative carbonyl content in total protein; initial specific activity $\left[0.469 \cup(\mathrm{mg} \text { protein })^{-1}\right]$ was taken as 1 , mean value of three experiments, mean standard deviation $10.8 \pm 3.5 \%$. (b) $O$, Relative GS activity; initial specific activity ( $1.78 \mathrm{U} \mathrm{mg}$ protein ${ }^{-1}$ ) was taken as $1 . \triangle$, Relative specific radioactivity in total protein; initial specific radioactivity [395.4 c.p.m. ( $\mu$ g protein) ${ }^{-1}$ ] was taken as $1 . \quad$, Relative carbonyl content in total protein; initial specific activity $\left[0.457 \cup(\mathrm{mg} \text { protein })^{-1}\right]$ was taken as 1.

contrast, the culture without nutrients had increased its GS activity by $16 \%$ after $3 \mathrm{~h}$ without aeration. Upon aeration of this culture, GS activity also decreased according to the air to liquid ratio (Fig. 1). Different degrees of hyphal adhesion were also observed in this experiment. The higher the air-to-liquid ratio the more hyphal adhesion was observed. Hyphae adhered into a single clump in the culture with the highest air-to-liquid ratio. Thus, both adhesion and GS activity loss are directly related to the amount of aeration to which hyphae are subjected. Hyphal adhesion in the mycelial mat occurred within the first $40 \mathrm{~min}$ of exposure to air. During hyphal adhesion, maximal redox imbalance occurred within the first 5-10 min of exposure to air and initial values were obtained after 30-40 min (Toledo et al., 1991). It was also observed that increased total protein oxidation was maximal at 15-20 min exposure to air and minimal at 30-40 min (Toledo \& Hansberg, 1990). Thus, GS activity in the air-exposed hyphae of a mycelial mat should decrease rapidly and then increase to the initial value during recovery from the hyperoxidant state. Enzyme activity was measured in cell extracts made from mycelial mats exposed to air for intervals of minutes. As shown in Fig. 2(a), GS activity decreased rapidly as soon as the mycelium was exposed to air (first transition). After a minimum at $20 \mathrm{~min}$, the activity recovered to the initial value at $45 \mathrm{~min}$ air exposure. Activity loss followed closely an increase in protein carbonyl content, which is a measurement of total protein oxidation (Ahn et al., 1987; Toledo \& Hansberg, 1990). Also, a high rate of proteolysis, determined by the solubilization of the radioactive label incorporated into protein, started as soon as hyphae were exposed to air and continued up to $45 \mathrm{~min}$ when protein oxidation had diminished and GS activity had attained the initial value (Fig. 2a). In contrast, GS activity remained constant in the unadhered hyphae of the mycelial mat, carbonyl content decreased to very low levels after a brief transient increase, and protein degradation was low (Fig. 2b).

To be certain that activity loss in the adhering hyphae was due to GS oxidation, GS was immunoprecipitated from the adhered and unadhered hyphae of a mycelial mat exposed to air for $30 \mathrm{~min}$ and the immunoprecipitates were analysed by two-dimensional electrophoresis. The GS from the unadhered hyphae presented only the usual $\alpha$ and $\beta$ polypeptides, as observed in extracts from growing hyphae (Sánchez et al., 1980) (Fig. 3a). In contrast, the GS from the adhered hyphae showed two other ones beside these polypeptides, $\alpha^{\prime}$ and $\beta^{\prime}$, similar to the first ones in molecular mass but more acidic (Fig. 3b). The same $\alpha^{\prime}$ and $\beta^{\prime}$ polypeptides were observed when the purified GS was treated with a source of hydroxyl radicals or when GS was immunoprecipitated from an extract of an aerated liquid culture that was carbon-starved, a condition under which the enzyme is degraded (Mora et al., 1980; Aguirre \& Hansberg, 1986). The present experiments indicate that GS is oxidized in mycelium exposed to air. Since the oxidized polypeptides are more prone to attack by endogenous proteolytic activities, GS is probably degraded and then resynthesized. Restoration of GS activity coincided with less protein oxidation and proteolysis at the end of the cell adhesion process.

Because a hyperoxidant state was also observed at the start 


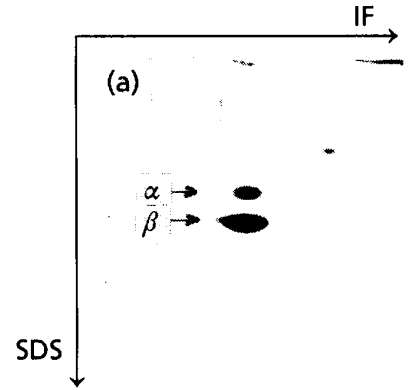

(b)

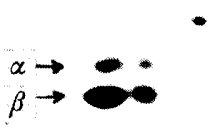

Fig. 3. Two-dimensional electrophoresis of GS immunoprecipitates. (a) Cell extract of the unadhered hyphae; (b) cell extract of the adhered hyphae after $30 \mathrm{~min}$ exposure to air. IF, isoelectric focusing; SDS, migration in the presence of SDS. The polypeptides migrated $63.5,66.5 \mathrm{~mm}$ in the first dimension, and $75.0,78.0 \mathrm{~mm}$ in the second dimension.

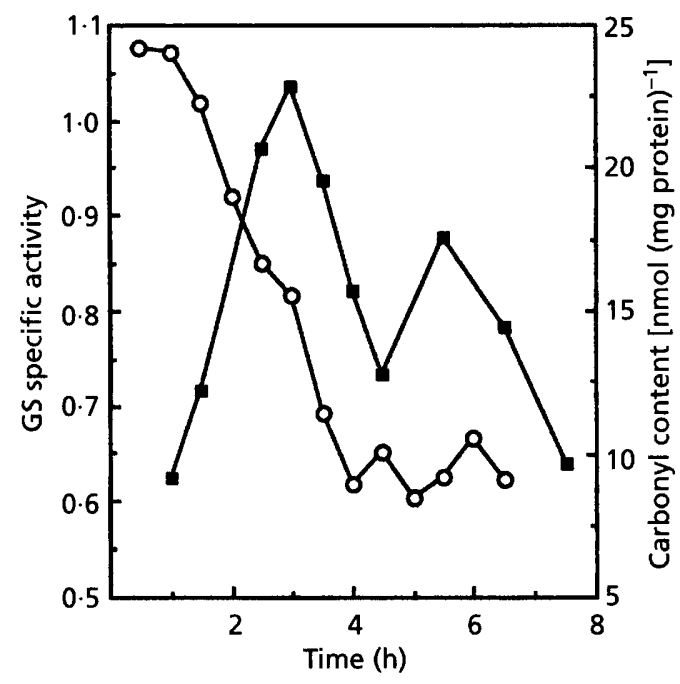

Fig. 4. GS specific activity and total protein oxidation during aerial hyphae development. $O$, GS specific activity; mean values of five experiments, mean standard deviation $17 \cdot 1 \pm 5 \cdot 2 \%$. Total protein carbonyl content, taken from Toledo \& Hansberg (1990).

of aerial hyphae development (second transition), regained GS activity in the adhered hyphae should decline before appearance of aerial hyphae. Enzyme activity was measured at $30 \mathrm{~min}$ intervals in the adhered hyphae. It was observed that GS activity was lost again after $1 \mathrm{~h}$ air exposure, coinciding with the start of increased protein oxidation (Fig. 4). Correlation between GS activity and carbonyl content in total protein was less clear than

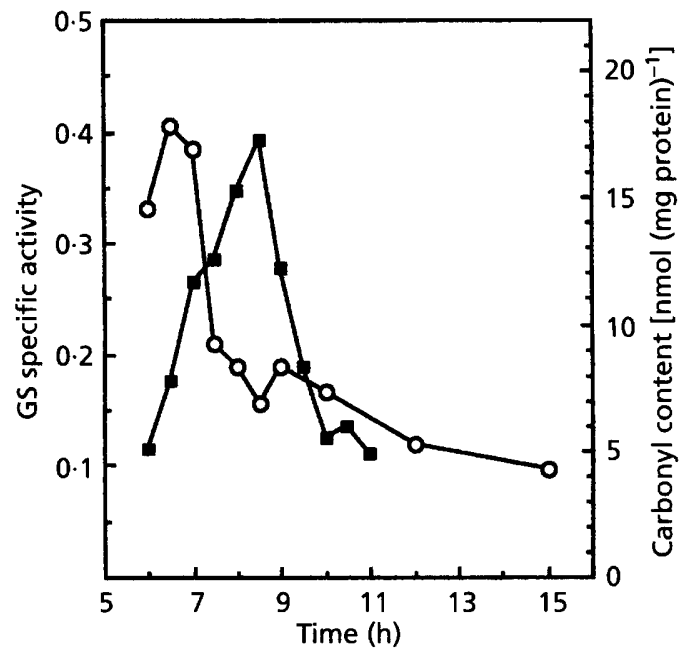

Fig. 5. GS specific activity and total protein oxidation during conidia formation. $O$, GS specific activity; mean values of two experiments. Total protein carbonyl content, taken from Toledo \& Hansberg (1990).

during hyphal adhesion. This could be due to some variance in the time course between experiments, related to the amount of water in the mycelial mat. Time course variance in the whole differentiation process $(15 \mathrm{~h})$ is $\pm 20 \mathrm{~min}$. Also, from the start of aerial hyphae formation at $2.5 \mathrm{~h}$ to about $6 \mathrm{~h}$, the aerial hyphae cannot be separated easily from the adhered hyphae. However, the contribution of aerial hyphae is quantitatively unimportant, representing less than $1 \%$ of the biomass.

The adhered hyphae autolyse, giving rise to a new increase in protein oxidation and proteolysis. The $\mathrm{NAD}(\mathrm{P}) \mathrm{H}$ and glutathione in the adhered hyphae are increasingly oxidized after $3 \mathrm{~h}$ (I. Toledo, P. Rangel \& W. Hansberg, unpublished results), indicating an oxidative state from which cells do not recover. Thus GS activity in the adhered hyphae does not recover with the appearance of aerial hyphae but activity continued to decrease after $6 \mathrm{~h}$ (Cárdenas \& Hansberg, 1984).

Similarly to the two preceding morphogenetic processes, GS activity in aerial hyphae was also lost at $6.5 \mathrm{~h}$ air exposure, before formation of conidia (third transition), coinciding with the start of increased protein oxidation (Fig. 5). A burst of conidiation occurred at 8.5-9.5 h air exposure. Although protein oxidation diminished with conidiation, GS activity showed very little concurrent increase. No GS activity was observed in isolated conidia. Also no mRNA for GS was detected in the prepackaged mRNA present in conidia. During germination the mRNA and GS activity increased in parallel, indicating a regulation at the transcriptional level (Hansberg et al., 1979).

These results are consistent with our previous data that indicate a hyperoxidant state at the start of each morphogenetic transition of the conidiation process. In 


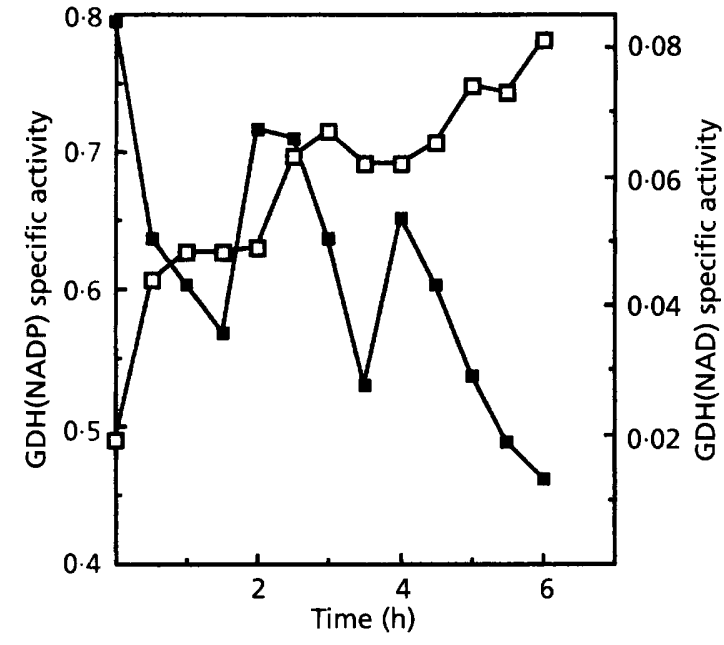

Fig. 6. $G D H(N A D P)$ and $G D H(N A D)$ specific activity during aerial hyphae development. $\mathbf{n}, \mathrm{GDH}(\mathrm{NADP})$ specific activity; mean values of four experiments, mean standard deviation $12 \cdot 7 \pm 7 \cdot 1 \% . \square, G D H(N A D)$ specific activity; mean values of two experiments.

all three cases GS activity loss coincided in time with the start of increased total protein oxidation. Thus GS seems to be highly susceptible to an in vivo oxidative modification.

\section{GDH activities during conidiation}

During hyphal adhesion (first transition) GDH(NADP) activity decreased moderately without recovery and continued to decrease during aerial hyphae development (second transition), with a partial recovery at 2 and at $4 \mathrm{~h}$ and a definitive loss thereafter (Fig. 6). In contrast, the catabolic enzyme behaved in an almost opposite manner to the biosynthetic enzyme: whenever the GDH(NADP) activity decreased, the GDH(NAD) increased; when the first one increased the second one remained without change (Fig. 6). Increased protein oxidation coincided with the GDH(NADP) loss and the increase in GDH(NAD) activity (Figs 4 and 6 ).

The GDH(NADP) was shown to be highly resistant to an oxidative modification. However a site-specific oxidative modification occurred when a dicarboxylic acid chelating iron was bound to the allosteric site (Aguirre et al., 1989). Thus, oxidation of GDH(NADP) required an intracellular availability of free iron and dicarboxylic acids. These conditions could be met during a hyperoxidant state because superoxide and hydrogen peroxide can release iron from iron-proteins (Halliwell \& Gutteridge, 1990). Thus, oxidation of GDH(NADP) requires the establishment of a hyperoxidant state. In contrast to GS, in which activity loss paralleled the increase in protein oxidation, loss of GDH(NADP) occurred when protein oxidation was already in progress.

The observed changes in GDH(NAD) are intriguing because its activity increased under oxidative conditions.
However, we do not expect all enzymes to be oxidatively inactivated; some may be resistant to oxidation, others may be modified but not affected in their activity and some may be activated by an oxidative modification.

We were not able to detect the modified GDH(NADP) polypeptides by immunoprecipitation in a cell extract from the adhering hyphae. Most of the in vitro modified GDH(NADP) polypeptides in the presence of a hydroxyl radicals source precipitated (Aguirre et al., 1989). Thus, this could also happen in vivo, or alternatively the oxidatively modified polypeptides could be degraded rapidly. However, antibodies against purified GDH(NADP) could be used to determine the amount of remaining unmodified polypeptide. Immunoprecipitates of cell extracts from adhering hyphae, adhered hyphae at the end of development, and unadhered hyphae were made and analysed by SDS-PAGE. The immunoprecipitate from a mycelial mat exposed to air for $20 \mathrm{~min}$ did not show differences compared to the one of an unexposed mycelium (first transition) (Fig. 7, lanes 6 and 7). However, after $15 \mathrm{~h}$ air exposure, the GDH(NADP) polypeptide in the adhered hyphae had almost disappeared (second transition) (lane 5). In contrast, the enzyme was preserved for $15 \mathrm{~h}$ in the unadhered hyphae (lane 4). In the same gel it is also shown that the disappearance of the GDH(NADP) polypeptide in a culture transferred to a medium without carbon source occurred only when the culture was aerated; in the non-aerated culture without carbon source the GDH(NADP) polypeptide was preserved (Fig. 7, lanes 2 and 3). From these experiments it is concluded that the disappearance of the GDH(NADP) polypeptide, like the GS polypeptides, is related to oxidizing conditions in hyphae exposed to air and in the carbon-limited culture.

In aerial hyphae no GDH(NADP), but a high GDH(NAD) activity, was detected (Cárdenas \& Hansberg, 1984). No GDH(NADP) polypeptide was detected in aerial hyphae or conidia (not shown).

\section{Return to the growing state}

After $15 \mathrm{~h}$ of air exposure, the unadhered hyphae have preserved GS and GDH(NADP) activity, and are thus similar to growing hyphae. If these enzymes are preserved in the unadhered hyphae because they are under a nearanaerobic condition (Toledo $e t$ al., 1991), a hyperoxidant state should develop in these hyphae when they are put back to fresh growth medium and aerated. Hyphae should adhere to each other, lose their GS and GDH(NADP), and should not start growing until they have regained these enzyme activities. In contrast, the GDH(NAD) should increase first and then decrease before growth begins. Adhered hyphae of the mycelial mat and aerial hyphae, however, because they have differentiated upon exposure to air, will not develop a hyperoxidant state when incubated in growth medium. Because they have lost their GS and GDH(NADP) activities, they require to induce these activities to start growing and the high GDH(NAD) activity should decrease from the beginning of incubation. 


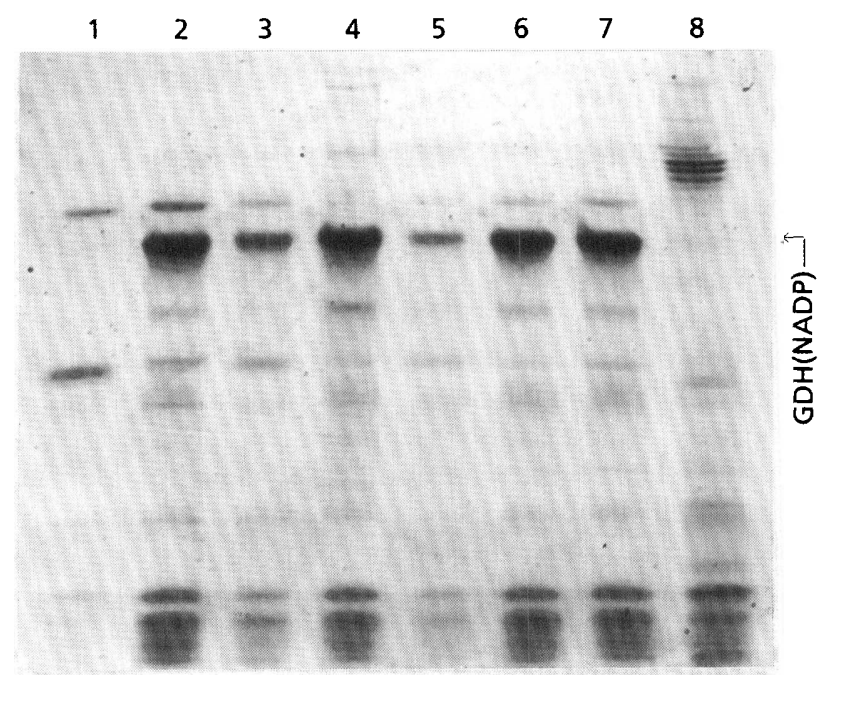

Fig. 7. SDS-PAGE of GDH(NADP) immunoprecipitates from different cell extracts. Lane 1, GDH(NADP) deleted mutant strain am-132; lane 2, liquid culture incubated for $4 \mathrm{~h}$ without carbon source in the absence of air; lane 3, liquid culture incubated for $4 \mathrm{~h}$ without carbon source in the presence of air; lane 4, unadhered hyphae of a mycelial mat after $15 \mathrm{~h}$ exposure to air; lane 5 , adhered hyphae of a mycelial mat after $15 \mathrm{~h}$ exposure to air; lane 6, mycelium unexposed to air; lane 7, adhering hyphae of a mycelial mat after 20 min exposure to air; lane 8 , rabbit anti-GDH(NADP) $\gamma$ globulin.

As expected, when incubated in a growing medium, unadhered hyphae adhered to each other during the first $2 \mathrm{~h}$ of aeration. GS activity decreased $75 \%$ and started to increase subsequently up to twice the initial activity (Fig. 8a). Similarly, GDH(NADP) activity decreased $95 \%$ during the first $4 \mathrm{~h}$ and then increased in the next $4 \mathrm{~h}$ to the initial value. In contrast, the already high GDH(NAD)

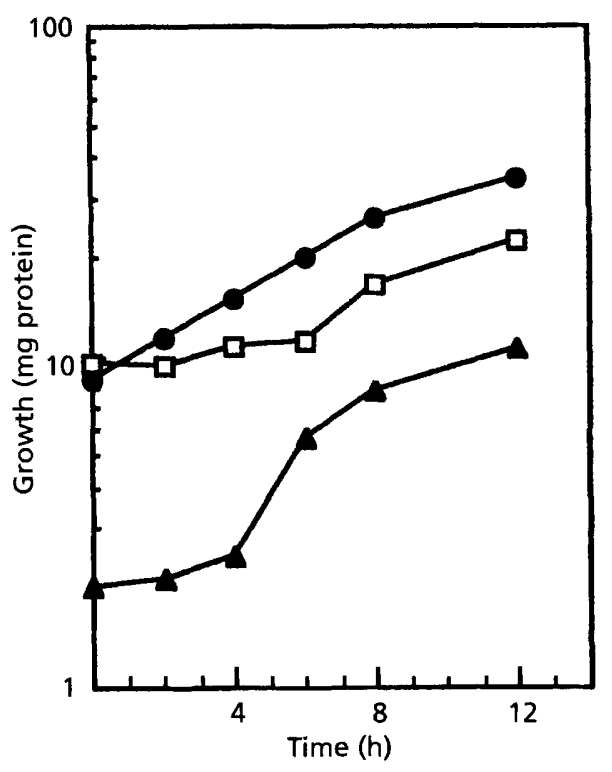

Fig. 9. Growth of the different cell structures of a mycelial mat transferred to growth medium after $15 \mathrm{~h}$ air exposure. $\square$, Unadhered hyphae; 0 , adhered hyphae; $\Delta$, aerial hyphae.

activity increased $55 \%$ during the first $2 \mathrm{~h}$ and then decreased to very low values (Fig. 8a). Growth started after $6 \mathrm{~h}$ incubation (Fig. 9).

In the adhered hyphae (Fig. 8b) and aerial mycelium (Fig. $8 \mathrm{c}$ ), the initial decrease in GS and GDH(NADP) activities was less pronounced or absent and induction of these enzymes started $2 \mathrm{~h}$ after start of incubation. The initially high GDH(NAD) activity decreased from the beginning. Growth started right away in the adhered hyphae and after $2 \mathrm{~h}$ in the aerial mycelium (Fig. 9).
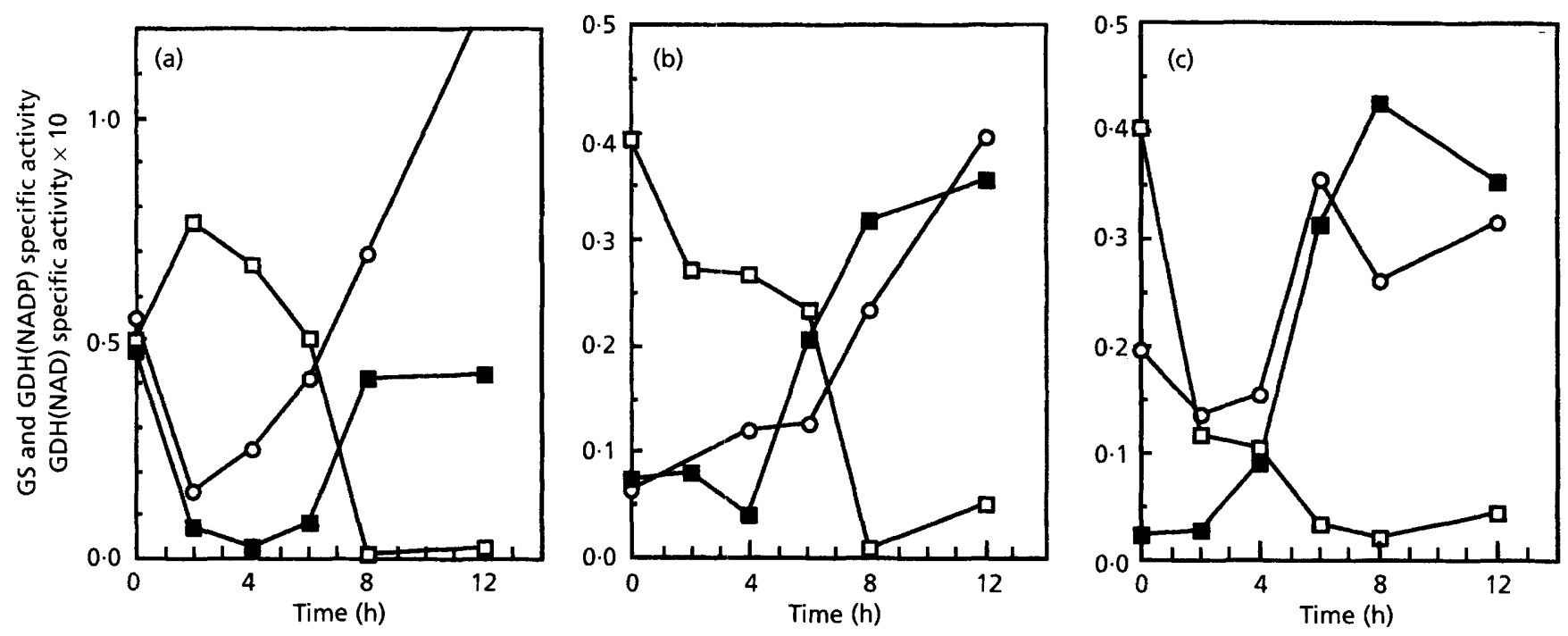

Fig. 8. GS (O), GDH(NADP) ( $\square$ ) and GDH(NAD) ( $\square$ ) specific activity of the different cell structures of a mycelial mat transferred to growth medium after $15 \mathrm{~h}$ exposure to air. (a) Unadhered hyphae, (b) adhered hyphae, (c) aerial hyphae. 
Taken together, the present data indicate that changes in activity of the three enzymes studied correlate with changes in oxidizing conditions during growth and differentiation. During growth in liquid cultures aeration is a limiting factor because of low solubility of dioxygen in water and high $\mathrm{O}_{2}$ consumption rate by growing micro-organisms. Under these conditions, enzyme activity is regulated by the rate of enzyme synthesis. However, under conditions in which aeration exceeds $\mathrm{O}_{2}$ consumption, or when reducing equivalents are limiting, enzyme activity is determined by the rate of enzyme oxidation, which can inactivate an enzyme, as in the case of the GS, and/or increase the rate of enzyme degradation. Because protein oxidation correlates with proteolysis, the inactivation and or degradation of GS and GDH(NADP) and a concomitant increase in GDH(NAD) activity makes physiological sense: carbon skeletons from amino acid degradation would drain into the tricarboxylic acid cycle to meet the requirement for reducing equivalents.

Hyphal adhesion is the first transition in the conidiation process. Adhesion also occurred in an aerated liquid medium when aeration was increased, or when carbon source was limiting, or when the loose anaerobic hyphae of the mycelial mat were transferred to an aerated growing medium. In each case hyphal adhesion coincided with loss of GS and GDH(NADP) activity and increase of GDH(NAD) activity. Adhesion occurred as a response to a hyperoxidant state generated under different stress conditions. It could be a resource to rapidly reduce the surface to volume ratio and thus permeation of $\mathrm{O}_{2}$ to most cells in a culture. Hyphal adhesion, development of aerial hyphae and formation of conidia all start with a hyperoxidant state in which similar changes in enzyme activity were observed. These results are consistent with the Dioxvgen Avoidance Theory which proposes that a recurrent hyperoxidant state drives cells from one stable state to another until a final differentiated state is reached where no hyperoxidant state normally occurs. With each differentiated state cells become more insulated from environmental dioxygen (Hansberg \& Aguirre, 1990).

\section{ACKNOWLEDGEMENT}

This research was supported in part by the Consejo Nacional de Ciencia y Tecnología, México, grant 0536 N9108 to W.H.

\section{REFERENCES}

Aguirre, J. \& Hansberg, W. (1986). Oxidation of Neurospora crassa glutamine synthetase. J Bacteriol 166, 1040-1045.

Aguirre, J., Rodríguez, R. \& Hansberg, W. (1989). Oxidation of Neurospara crassa NADP-specific glutamate dehydrogenase by activated oxygen species. J Bacteriol 171, 6243-6250.

Ahn, B., Rhee, S. G. \& Stadtman, E. R. (1987). Use of fluorescein hydrazide and fluorescein thiocarbazide reagents for the fluoro- metric of protein carbonyl groups and for the detection of oxidized protein on polyacrylamide gels. Anal Biochem 161, 245-257.

Cárdenas, M. E. \& Hansberg, W. (1984). Glutamine metabolism during aerial mycelium growth of Neurospora crassa. J Gen Microbiol 130, 1733-1741.

Ferguson, A. R. \& Sims, A. P. (1971). Inactivation in vivo of glutamine synthetase and NAD-specific glutamate dehydrogenase: its role in the regulation of glutamine synthesis in yeast. $J$ Gen Microbiol 69, 423-427.

Fincham, J. R. S. (1957). A modified glutamic acid dehydrogenase as a result of gene mutation in Neurospora crassa. Biochem J 65, 721-728.

Halliwell, B. \& Gutteridge, J. M. C. (1990). Role of free radicals and catalytic metal ions in human disease: an overview. Methods Enzymol 186, 1-85.

Hansberg, W. \& Aguirre, J. (1990). Hyperoxidant states cause microbial cell differentiation by cell isolation from dioxygen. $J$ Theor Biol 142, 201-221.

Hansberg, W., de Groot, H. \& Sies, H. (1993). Reactive oxygen species associated with cell differentiation in Neurospora crassa. Free Rad Biol \& Med 14, 287-293.

Kinsey, J. A. \& Hung, B. T. (1981). Mutation at the am locus of Neurospora crassa. Genetics 99, 405-414.

Mora, Y., Chávez, O. \& Mora, J. (1980). Regulation of Neurospora crassa glutamine synthetase by the carbon and nitrogen source. $J$ Gen Microbiol 118, 455-463.

O'Farrell, P. H. (1975). High resolution two-dimensional electrophoresis of proteins. J Biol Chem 250, 4007-4021.

Sánchez, F., Campomanes, M., Quinto, C., Hansberg, W., Mora, J. \& Palacios, R. (1978). Nitrogen source regulates glutamine synthetase mRNA levels in Neurospora crassa. J Bacteriol 136, 880-885.

Sánchez, F., Calva, E., Campomanes, M., Blanco, L., Guzmán, J., Saborio, J. L. \& Palacios, R. (1980). Heterogeneity of glutamine synthetase polypeptides in Neurospora crassa. J Biol Chem 255, $2231-2234$.

Sies, H. \& Akerboom, P. M. (1984). Glutathione disulfide (GSSG) efflux cells and tissues. Methods Enzymol 105, 445-451.

Springer, M. L. \& Yanofsky, C. (1989). A morphological and genetic analysis of the conidiophore development in Neurospora crassa. Genes Devel 3, 559-571.

Toledo, I. \& Hansberg, W. (1990). Protein oxidation related to morphogenesis in Neurospora crassa. Exp Mycol 14, 184-189.

Toledo, I., Aguirre, J. \& Hansberg, W. (1986). Aerial growth in Neurospora crassa: characterization of an experimental model system. Exp Mycol 10, 114-125.

Toledo, I., Noronha-Dutra, A. A. \& Hansberg, W. (1991). Loss of $\mathrm{NAD}(\mathrm{P})$-reducing power and glutathione disulfide excretion at the start of induction of aerial growth in Neurospora crassa. J Bacteriol 173, 3243-3249.

Vogel, H. J. (1964). Distribution of lysine pathways among fungi: evolutionary implication. Am Nat 98, 435-446.

Received 1 February 1994; revised 16 March 1994; accepted 12 April 1994. 